\title{
ERS and ISAM: a significant progression
} For decades, the concept of administering
drugs directly into the bronchial tree, in the form of aerosols, has been the cornerstone of therapy in pneumology. Spray technology was initially developed in the middle of the 19th century, but the concept of aerosol therapy was really born with the discovery of adrenaline and epinephrine at the beginning of the 20th century. According to a paper published in 1936 [1], the first case of asthma treated with aerosolised adrenaline was reported in 1912. Pictures dating from this era illustrate the kinds of materials that were used, probably resulting in dissemination of the drugs more around the patient than in the respiratory tract itself[2]! However, even with such poor technical conditions, bronchodilation with $\beta$-agonists was so efficient that it stimulated technological research, leading to the design of metered-dose inhalers in the early 1950s. From that time, aerosol therapy became the subject of active research both in the field of devices, with the development of ultrasonic and jet nebulisers in the 1950s, and in the field of formulations, leading to the discovery of new drugs such as beclomethasone, which revolutionised the treatment of asthma in the early 1970s.

Meanwhile, physical and physiological studies led to an increased understanding of the concept of aerosol particle size, how to measure it and how it influences aerosol deposition in human lungs, especially if diseased. It soon became obvious that the successful development of aerosols in medicine would require the interaction of scientists from various backgrounds, including physics, chemistry, physiology and medical science, and this resulted in the creation of the International Society for Aerosols in Medicine (ISAM), in which representative experts have progressively gathered.
Today, ISAM includes $\sim 300$ members, of whom about $50 \%$ are Europeans. Members can freely communicate through a newsletter and the society's website (www.isam.org), where information regarding the society and its events, as well as useful web links, is available. The Journal of Aerosol Medicine (JAM), ISAM's official publication, is published quarterly. The editorial policy of the JAM is to publish peer-reviewed research in the field of aerosol medicine, and, as a result of the interest in the journal, there has been a continuous increase in its impact factor, up to 1.58 in 2004. Every 2 years, ISAM organises a congress to enable scientists who are committed to the progress of aerosol therapy to interact and exchange recent research findings. The next congress will be in Tours (France) on June 16-20, 2007 and will be endorsed by the European Respiratory Society (ERS), with whom ISAM is forging stronger links.

ISAM is also developing interactive relationships with other sister societies, including, to name a few, the American Thoracic Society (ATS), the American Association for Aerosol Research (AAAR) and the American Association of Respiratory Care (AARC). Indeed, as a key player in the field of aerosol therapy, the ISAM would make a natural partner with other societies that are interested in increasing their educational programmes. Such a partnership may be particularly useful considering that aerosol therapy has increased not only in its applications, but also in its complexity during the last few years.

Aerosolised antibiotic therapy is now considered a standard of care in treating cystic fibrosis, and its use requires considerable expertise [3]. In addition, the administration of prostacyclin and synthetic analogues by aerosol is one of the new therapeutic approaches for pulmonary

\section{P. Diot ${ }^{1}$ \\ W. $\mathrm{MaCNee}^{2}$ \\ W. Kreyling ${ }^{3}$ \\ R. Dahl' \\ B. Laube \\ G. Viegi}

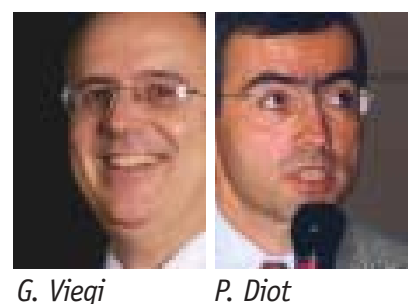

G. Viegi P. Diot

${ }^{1}$ President Elect, ${ }^{3}$ Past President and ${ }^{5}$ President of the

International Society for Aerosols in Medicine (ISAM;

www.isam.org).

${ }^{2}$ President Elect, ${ }^{4}$ Past President and ${ }^{6}$ President of the European Respiratory Society (ERS; www.ersnet.org). 
The ERS and ISAM organised a joint course in Budapest, in November 2005, on Medical aerosols. Material presented can be found at www.ersnet.org/elearning

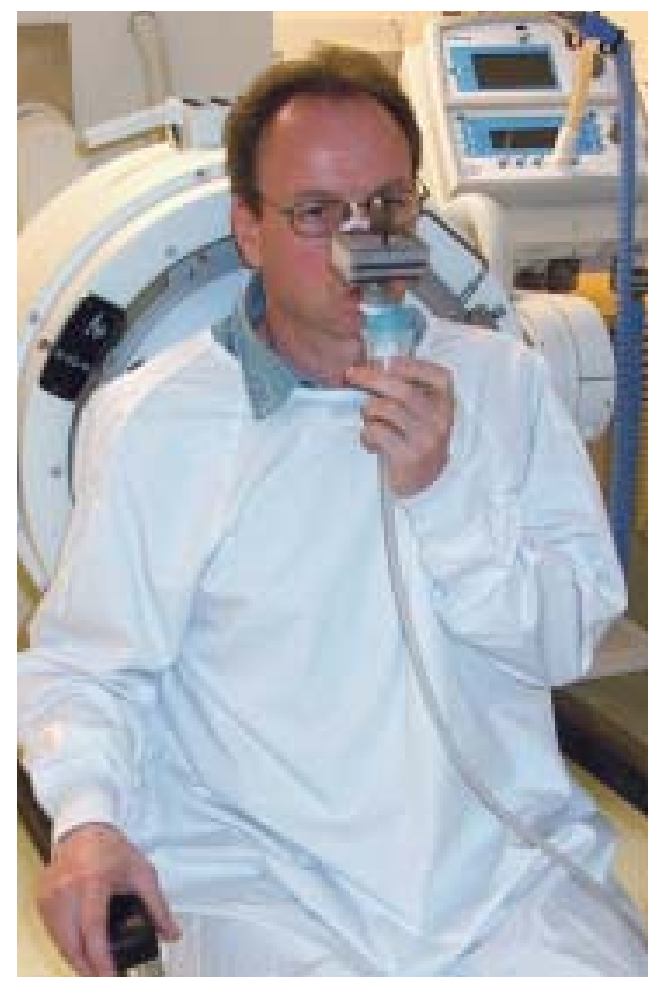

hypertension, and the use of these aerosolised drugs has dramatically improved the prognosis of this orphan disease [4]. Another exciting development in aerosol medicine is that inhaled insulin, whose pharmacokinetic characteristics were first published in the JAM [5], is close to approval for treating patients with diabetes in both the USA and Europe. The aerosol route of administration may also be a promising strategy to administer chemotherapy in patients with lung cancer [6], and the list of drugs administered by this route will be even longer in the near future. From a device manufacturer's point of view, new, more efficient devices to generate aerosols have recently been introduced, and this was the subject of an ERS/ISAM School Course on medical aerosols which took place in Budapest (Hungary) on November 25-26, 2005. In the next issue of Breathe, L. Vecellio presents a review on vibrating mesh nebulisers, which are among the new devices with which the respiratory physician needs to become familiar.

ISAM is also involved in research about the effects of inhaled air pollutants on health, and in imaging techniques that are used to study airway physiology and its relationship with aerosol deposition and clearance from the respiratory tract.

For all these reasons, it has become clear to the ERS and ISAM leadership that a strong relationship between the two societies would be beneficial to both. Therefore, we are pleased to announce that an official ERS/ISAM Joint Membership agreement has recently been signed, allowing interested colleagues to get a discount of $15 \%$ in the membership fee from each of the two societies. Both societies will soon install links on their websites and will advertise upcoming meetings in their respective journals. In the future, it is hoped that editorials and opinions from ISAM members may be published in the ERS Newsletter and in the JAM. Furthermore, both the ERS and ISAM are engaged in establishing a Task Force to prepare guidelines on the use of imaging in the field of aerosol medicine. A combined ERS/ISAM symposium will also be organised during the forthcoming ISAM Congress in 2007. Joint membership will also enable ERS and ISAM members to access the educational materials found in the ERS e-learning resources centre (www.ersnet.org/e-learning), and publications such as Breathe, the $E R J$ and $J A M$, thereby increasing their knowledge of the field of aerosol therapy, which, over time, has become a basic necessity for every pneumologist in the world.

\section{References}

1. Nelsen NA. Treatment of asthmatic attacks by inhalation of adrenaline. Lancet 1936; 846-849.

2. Dessanges JF. A history of nebulization. J Aerosol Med 2001; 14: 65-71.

3. Diot P, Dequin PF, Rivoire B, et al. Aerosols and anti-infectious agents. J Aerosol Med 2001; 14: 55-64.

4. Schermuly R, Schulz A, Ghofrani A, et al. Comparison of pharmakokinetics and vasodilatory effect of nebulized and infused iloprost in experimental pulmonary hypertension - rapid tolerance development. J Aerosol Med 2005; (In press).

5. Laube B. Insulin level, relative bioavailability, and effects of site deposition of nebulized insulin in patients with noninsulin-dependent diabetes mellitus. J Aerosol Med 1998; 11: 153-173.

6. Gagnadoux F, Le Pape A, Urban T, et al. Safety of pulmonary administration of gemcitabine in rats. J Aerosol Med 2005; 18: 198-206. 